\title{
Geological environmental factors of resident's cancer distribution in Beijing-Tianjin Corridor
}

\author{
Jin-zhong Gong *
}

\author{
Hebei Institute of Geophysical Exploration, Langfang 065000, China.
}

World Journal of Advanced Engineering Technology and Sciences, 2021, 03(02), 024-037

Publication history: Received on 01 September 2021; revised on 23 October 2021; accepted on 25 October 2021

Article DOI: https://doi.org/10.30574/wjaets.2021.3.2.0068

\begin{abstract}
The corridor region between Beijing and Tianjin in China belongs to the alluvial and proluvial sedimentary plains of different water systems, and the social economy is very developed. By personally interviewing local villagers, the author obtained data on cancer morbidity and mortality at the village level. Using GIS operating platform, the author makes contour map, its value ranges from 10/10,000 to 100/10,000 and has significant zonal distribution characteristics. The authors analyzed the relationship between cancer distribution and natural geography, soil and hydrogeochemical data in the region, the results showed that there was a significant negative correlation $\left(n=222, \gamma_{0.05}=0.163\right)$ : shallow water level buried depth -0.4218 , surface soil $\mathrm{pH}-0.3702$, altitude elevation -0.3448 , surface soil $\mathrm{SiO}_{2}-0.3158$, significant positive correlation: surface soil $\mathrm{Pb} 0.5769$, Cd0.4629, deep soil $(-1.3 \mathrm{~m})$ N0.5518, $\mathrm{Hg} 0.4321$, surface soil Mo0.3486, $\mathrm{Cu} 0.3340$, As0.3234, $\mathrm{Fe}_{2} \mathrm{O}_{3} 0.2913$, $\mathrm{Mn} 0.2906, \mathrm{U} 0.2882$, F0.2833, shallow groundwater $\mathrm{NH}_{4} \mathrm{~N} 0.2768$, surface soil V0.2835, Ni0.2707, F0.2604, Cr0.2460, Tl0.2241, shallow groundwater As0.2199,Cd0.2109, $\mathrm{NO}_{3} 0.1644$. According to the characteristic pollutant frequency table of 340 key industries in Langfang area, the correlation coefficient of organic pollutants and mercury was calculated: benzopyrene 0.4723 , pyridine 0.1551 , formaldehyde 0.1371 , dioxin 0.1138.Based on the results of this study, the authors established a mode chart of the relationship between geochemical anomalies (contamination sources) of soil waters- geotechnical hydrological conditions (migration pathways)-resident cancer distribution (sensitive receptors).
\end{abstract}

Keywords: Cancer distribution map; Soil and groundwater; Geological geochemistry; Relationship model; BeijingTianjin Corridor region

\section{Research progress on the relationship between cancer and ecological environment}

From the late 1990s to the present, people have paid more attention to the relationship between soil and human cancer, and pollutants with clear cancer risk. The high-low incidence areas of gastric, esophageal and liver cancer in China have regional distribution characteristics and unique geological environments. Some elements of soil, drinking water, food, and human body were significantly positively or negatively correlated with the incidence [1] [2] . Regression analysis showed that gastric cancer was positively correlated with soil $\mathrm{Pb}$ and negatively correlated with Mo and Se [3]. Elements such as $\mathrm{Pb}, \mathrm{K}, \mathrm{As}$, and $\mathrm{Cr}$ in human hair are positively correlated with local malignant tumor mortality [4]. The geographical distribution of cancer villages in China is consistent with the distribution of water pollution and air pollution. There is a positive correlation between the number of cancer villages in each province and the to tal GDP of each province [5].

With the rapid development of the economy and society and the improvement of the living standards of urban and rural residents, the age structure, eating habits, lifestyles, and environmental conditions of the Chinese population have undergone major changes, the disease epidemic pattern has undergone major transformation. In 2006, chronic non-

\footnotetext{
* Corresponding author: Jin-zhong Gong

Hebei Institute of Geophysical Exploration, Langfang 065000, China. 
communicable diseases such as cerebrovascular diseases and malignant tumors have become the main cause of death in urban and rural residents. From the crude mortality rate of malignant tumors, city is $16.7 \%$ higher than rural area, the eastern city is 24.9 higher than the western city, and the eastern rural area is $43.7 \%$ higher than the western rural area. Some cancer deaths have a phenomenon of village aggregation. In some areas, the mortality rate of cancer is at a national low or normal level. The cancer spectrum of urban and rural residents is changing, and it is increasingly becoming the pattern of cancer death in developed countries. There are significant differences in the level of malignant tumor death and lineage structure in different regions [6] .

Since the 1970s, the incidence and mortality of malignant tumors in China have continued to increase [7] .

Chen $W$, et al. expected in 2015 the incidence and mortality of lung cancer are the highest. The incidence and mortality of gastric cancer, esophageal cancer and liver cancer are also high. Age-standardized data on morbidity and mortality of all cancers, rural residents are higher than urban residents. 2000 2011, all cancers, the incidence of men remained stable, and the incidence of women increased significantly. In contrast, mortality has been declining since 2006 [8].

Due to the increase in the elderly population, the burden of cancer in the digestive tract in China is still serious, and cancers closely related to the environment and lifestyle, such as lung cancer and breast cancer, have increased significantly in recent years. It is expected that in the next few decades, China's cancer morbidity and mortality will continue to rise as a whole [9].

China's health industry has made tremendous progress, but the gap between regions still exists, and the heterogeneity of mortality in various regions is a concentrated expression of this. Maigeng Zhou., et al divided the regions of mainland China into five grades [10].

In 2014, the incidence rate of malignant tumors in Hebei Province was 224.98/100,000, and the mortality rate was 149.42/100,000. Mainly is lung cancer, stomach cancer, liver cancer, esophageal cancer and breast cancer. The combined incidence ,the incidence of lung cancer, liver cancer and breast cancer showed a fluctuating upward trend. The task of cancer prevention and treatment in the future is still arduous, and measures still need to be taken to continue to strengthen the prevention and control of malignant tumors in the province [11] .

The distribution of cancer villages in China is closely related to rivers. Nearly $60 \%$ of cancer villages are distributed within $3 \mathrm{~km}$ of rivers, and $81 \%$ of cancer villages are distributed within $5 \mathrm{~km}$ of rivers; The generate of cancer villages in China, its $95.16 \%$ is caused by chemical carcinogens. Environmental pollution, especially water pollution, is the chief culprit in the cancer village [12].

J. Z.Gong analyzed the influence mechanism of mine tailings reservoir on the hydrogeological environment of adjacent areas, established a conceptual model of local groundwater system and the dose-response function relationship between groundwater $\mathrm{NO}_{3}$-content and cancer incidence [13].

Many cancers occur in China have regional differences, the difference in living environment hidden behind the region is the real cause of the difference in cancer incidence. Using the data of regional differences as a clue to further investigate and discover the hidden risk factors, this is the significance of investigating the difference in incidence rates in different regions.

Based on the latest water soil geochemical survey and resident cancer incidence mortality data, using relevant analytical methods, this paper has studied the geological environment factors of cancer distribution in the Beijing-Tianjin Corridor region.

\section{Regional physical geography, social economy}

China Geological Environment Monitoring Institute "Atlas of water and soil geological environment in North China Plain", by reveal the current status and evolution of phreatic water and soil geological environment as the main line, starting from the study of spatial heterogeneity and time dynamics of single media, using the latest survey data and modern data processing technology, shows systematically the current status and evolution trend of water and soil geological environment in North China Plain, and the main characteristics of water and soil geological environment that affect economic and social sustainable development ${ }^{[14]}$.

The region is located in the plain between the east of the Taihang Mountains and the south of the Yanshan Hilly Area and the Bohai Bay. The main types of landforms are hills, tablelands, foothill plains and alluvial plains, dominated by 
alluvial plains. The plain area is large in area and wide in range, with an elevation of $5 \sim 26 \mathrm{~m}$. The depression lake district is distributed in Wen'an and Shengfang in the south, with an altitude of $4 \sim 2 \mathrm{~m}$. The general trend of the terrain is, higher in the northwest and southwest, lower in the middle and east, and it present a fanshaped tilt to the direction of the Bohai bay.

The region is rich in natural resources, with flat and fertile land, four distinct seasons of climate, diverse types of vegetation, and rich minerals. The terrain is flat and open, the stratum is deep thick, and the soil types are diverse, which is suitable for planting a variety of crops.

The region is located in the middle and lower reaches of the Haihe River, with developed water systems and 20 rivers flowing through the area. Generally, the average surface water can be retained 333 million $\mathrm{m}^{3}$ per year, and the water resources can be used 774 million $\mathrm{m}^{3}$.

Along the edge of the foothills, there are Quaternary red, reddish-brown colour, contains the gravel sub-clay and loesslike sub-sand, sub-clay and residual slope sand gravel, etc. Alluvial, flood deposition, aeolian deposition and marsh sediment are distributed clay, sub-clay, sub-sand, sand, ooze and peat in the plain area. It is generally $150 \sim 520$ meters thick, and the horizontal layered structure development, the matter composition varies greatly along the vertical.

The region is mainly composed of moisture soil. From the north hilly area to the south low-lying land area, it is stony soil- cinnamon soil - sand ginger black soil - moisture soil- marsh soil- meadow solonchak. The distribution of soil types is controlled by rivers and terrain. The distribution of soil varies greatly in the vertical direction, the sedimentary rhythm development, the sorting is clear, and profile form of soil body is changeable. Because the river has been migrated many times, sand and clay in sediments are variable, layers of sand and clay alternate with each other, and binary lenses are often present (Coarse at the bottom and fine at the top, and there is a sand or a sticky lens body).

The geochemical characteristics of soil are restricted by river basins, different basin have different combinations of enrichment and depletion elements. The structure and quantity of plant species in different watersheds are also different. The same basin, the number of species, upstream is higher than the downstream.

According to the occurrence conditions of groundwater and the pore characteristics of the aqueous medium, the groundwater in this area is divided into two major types of aquifers: loose rock pore water aquifer group, carbonate rock karst aquifer group.

The loose rock pore water-bearing rock group is mainly composed of Quaternary loose sediments, which are widely distributed in the central and southern plains. The aquifer is composed of sub-sand, sand and gravel. It has coarse grain size and large thickness. The hydrodynamic characteristics are phreatic water, micro-pressure water and confined water. The aquifer is from northwest to southeast, the particle size becomes smaller, the thickness becomes thinner, and the water-richness deteriorates. There are brackish water and salt water distribution in Dacheng County, Wen'an County and southeast of Anci District. According to the hydraulic properties and mining conditions of the aquifer, the groundwater in this area is divided into shallow groundwater and deep groundwater. In the whole freshwater area, the shallow water is the I+II water-bearing group; In the saline water distribution area, the shallow water is the shallow fresh water and brackish water above the salt water body roof.

Shallow groundwater types are basically infiltration - extraction - excretion type. Regional multi-year over-exploitation and climate drought are the main reasons for the continuous decline in water levels. Precipitation replenishment and seasonal mining during the year caused fluctuations in water levels during the year.

Precipitation and extraction volume are the main factors affecting the depth of shallow groundwater. These factors, combined with different hydrogeological conditions, make the groundwater depth show regional differences. The depth of shallow groundwater is between 10 and $20 \mathrm{~m}$, and the buried depth of individual sites is greater than $20 \sim 30 \mathrm{~m}$. The depth of groundwater in other areas is between 2 and $8 \mathrm{~m}$. The shallow depth of groundwater table is mainly restricted by altitude elevation, and there is a significant negative correlation between them. Followed by the deep basement structure pattern, there are many droping funnels in the uplift area, and in the depression area towns, the anti-funnel often appears.

The population density distribution of this district is the highest in Tianjin and Beijing 5000 20000 person $/ \mathrm{km}^{2}$, Followed by Langfang City 5000 1000 person $/ \mathrm{km}^{2}$, County-level city 1000-5000 person $/ \mathrm{km}^{2}$, rural area $100 \sim 800$ person $/ \mathrm{km}^{2}$, the lowest in the low-lying areas such as Baicaowa, Wen'anwa and Tuanbowa $<250$ person $/ \mathrm{km}^{2}$. 


\section{Ecological environment pollution status}

Environmental pollution has caused public grievances and even evolved into sensitive political issues. At present, the contradiction between rapid economic growth and environmental protection is still very sharp. The discharge of major pollutants in the country continues to rise, some projects with high energy consumption and high pollution are still expanding blindly. Environmental violations to continue despite repeated prohibition. The discharge of major pollutants exceeds the environmental carrying capacity, Water, atmosphere, soil and other pollution are becoming more and more serious. Solid waste, automobile exhaust, persistent organic matter and other pollution continue to increase, The rivers flowing through the city are generally polluted.

Zhang Weili et al. surveyed results showed that, due to the large-scale application of agricultural nitrogen fertilizer, the problem of nitrate pollution in groundwater and drinking water in some rural and small towns is very serious. More than half of the 69 sites exceeded the maximum allowances of drinking water, with the highest being $300 \mathrm{mg} / \mathrm{l}$ [15] .

According to the statistics of China Environmental Statistics Annual Report (2004): Since 1998, with the improvement of industrial development and urbanization, China's domestic sewage and industrial wastewater discharge has been continuously increasing. In 2004, the total discharge of wastewater in the country was 48.2 billion tons, the amount of industrial solid waste generated was 120.3 million tons, and the discharge was 17.62 million tons. The whole national hazardous waste production amounted to 9.95 million tons and the emissions were 11,000 tons. Domestic waste landfills and industrial solid waste dumps have a serious impact on groundwater, increasing the difficulty of pollution control and treatment.

Li Zhongchun pointed out that China's fertilizer utilization rate is not high, Nutrients that are not used by plants enter the environment through fixation, leaching and volatilization, causing soil plate harden and acidification, heavy metals such as copper, mercury and cadmium exceed the standard, atmospheric and water pollution [16].

Liu Qinpu studied the temporal and spatial variation of fertilizer application intensity and environmental safety threshold and the rationality of fertilization in China. The results show:1) Since 1980, the application rate of chemical fertilizers in China has increased rapidly, and the average growth rate of chemical fertilizer application intensity has been increasing every year 4.1\%.2) Beijing and Tianjin are ultra-high-strength fertilization areas;3) Environmental safety thresholds for chemical fertilizer application in more than $60 \%$ of provinces vary in the middle range; 4 ) In 2014 , the application intensity of chemical fertilizers in China was 1.2 times the environmental safety threshold; Excessive application of nitrogen and phosphate fertilizers is more serious, and insufficient application of potassium fertilizer is more common [17].

\subsection{Air pollution brings acid rain hazard}

According to the observation of the Langfang Monitoring Station of the Environmental Geology Station of Hebei Province from 1985 to 1990, the acid rain began in Langfang City since 1988, and the number of times has increased. According to the wind speed and wind direction analysis, the formation of five acid rains in this area was mainly caused by air pollution in the local and Beijing areas. According to the monitoring results of precipitation components, the acid rain frequency in Langfang City increased from 2001 to 2005. SO $4^{2-}$ is the main acid-producing substance of precipitation, and of $\mathrm{N}_{3}{ }^{-}$contribution has increased.

In the tide of reform and opening up, the region's economy has developed rapidly, population concentration, industrialization has increased, and motor vehicles have increased. This leads to an increase in emissions. Contaminants do not easily diffuse under static conditions in the atmosphere, causing pollution incidents near the ground layer has increased. The fog and haze weather is frequent, which has a serious impact on the people's production, life and physical and mental health.

The environmental protection department's 2013 air quality monitoring report showed that, among the 74 monitored cities, 71 cities have exceeded the air pollution standard, and the Beijing-Tianjin-Hebei region has the most serious pollution. Among the 13 cities, 7 cities are in the top 10, and some cities have more than $40 \%$ of the annual air pollution days. In 2013, the haze shrouded one-third of the country, and in 2014, the haze even more appeared frequently.

\subsection{Industrial three wastes causes soil pollution}

Regional soil geochemical surveys have shown that, in Langfang area, compared with deep soil $(-130 \mathrm{~cm})$, the arable soil $(0 \sim 20 \mathrm{~cm})$, nitrogen, mercury, cadmium, phosphorus and other elements are significantly increased, among them, Sanhe 
Gaolou-Dachang Xiadian, Sanhe Juyang-Zhaohegou, Sanhe Duanjialing, Sanhe Huangzhuang, Xianghe Shuyang, Langfang Development Zone, Bazhou City urban area and other areas have high content of mercury geochemical positive anomalies.The manganese-lead-cadmium-zinc in the Pengzhuang-Dazaolin area of Anci District, the molybdenum element in Mangdian in Anci District, the Dawujiangtai in Bazhou City, and the cadmium element in Nanzhaofu in Dacheng County all showed positive anomalous distribution.

In 2001, Langfang area coal consumption was 813,400 tons, exhaust gas emissions were 11.76762 billion standard cubic meters, soot emissions were 19,295 tons, wastewater discharge was 8,450 tons (rate of reaching the standard 72.91\%), and solid waste production was 579,300 tons (utilization rate of $95.18 \%$ ). Those parts that are not recycled will become an important source of pollution in the soil environment.

The pollution of the air, water and soil environment eventually reaches the body through the trophic level or the food chain. Preliminary biogeochemical surveys of major towns in the district indicate that, in Sanhe Gaolou, Huangzhuang, Guangyang Jianta, Jiuzhou, Yongqing Hancun and other places, Lead in the corn exceeds the national food hygiene standards by 2 7 times; In Bazhou City urban area, Shengfang, Wangzhuangzi, Langfang City, Sanhe Gaolou, Huangzhuang, etc, mercury in human hair content is higher; Xianghe Jinxinzhuang, Guangyang Jianta, Gu'an Zhiziying and Bazhou Wangzhuangzi, Wen'an Shigezhuang, etc. the content of lead in human hair is higher; Xianghe Jinxinzhuang, Guangyang Jianta, Jiuzhou, Yongqing Hancun, Anci Tiaohetou, human hair cadmium content is higher.

\subsection{Water pollution harms residents' health}

Due to the massive extraction of groundwater and oil and gas resources, the groundwater level in this area has been declining year by year, become a threshold that restricts urban development.

Water pollution is an important environmental issue that directly harms the health of residents. According to the sewage discharge data of Langfang City Water Resources Bureau in 1998, the sewage discharge in this area is dominated by industry, followed by lives of residents. Sewage sources are concentrated in densely populated, industrially developed regions, such as Langfang City, Sanhe City and Bazhou City. The main pollutants are COD, ammonia nitrogen, nitrate nitrogen, nitrite nitrogen, sulfide, fluoride, volatile phenol, manganese, mercury, chromium and other indicators.

According to Hebei Province Environmental Geology Station the laboratory data of shallow groundwater quality in 1999, evaluation using the Groundwater Quality Standard (GB/T14848-1993), the upstate three counties (Sanhe, Dachang, Xianghe) , 60\% of the area with poorer water quality, it is distributed in Huangtuzhuang, Yanjiao, Xinji, Dachang Chenfu, Xianghe Shuyang etc.; for $40 \%$ of the area with very poor water quality accounts, it is distributed in the north-central part of Sanhe City, the central and western parts of Dachang County and the outer periphery of Xianghe County. The main over-standard projects are total hardness, fluorine, iron and manganese, it is related to less precipitation, over-exploitation and primary geological environment. The region with poorer water quality in 7 counties in the south, the area is $27 \%$, it is distributed in the west of Anci to the whole freshwater area in the north of Gu'an and the southwest of Yongqing and the northern part of Bazhou. The rest is very poor water quality regions with an area of 73\%. The main over-standard items are total hardness, total dissolved solids, sulfate, iron, manganese and chloride.

\subsection{Typical environmental pollution disaster}

In March 2005, CCTV's "Oriental Time and Space" column, with the title of "Tianjin Xiditou Cancer Village Covered by Poisoning", the chemical pollution incident in the village was reported to the national audience.

In March 2006, Xiadiancun, Dachang County, Feng jun's two daughters have been suffering leukemia one after another. There is a rolling mill near his fish pond. drinking water samples total arsenic exceeded 2.95 times, and total manganese exceeded 3.8 times. He embarked on the road of petitions and complaints for 10 years.

May 26, 2009, The Langfang Environmental Protection Bureau imposed penalties on the discharges of sewage, dumping sludge and other environmental violations by Bazhou Meihua Bio-Group Co., Ltd. The pollution incident occurred in May 2009, and in November 2010, it caused the surrounding residents thousand acres of farmland to be lie wasted.

In 2010, the collection and processing of waste plastics began in Yincun, Zhaogezhuang Town, and has been distributed in 101 administrative villages in Wen'an County. Cleaning old plastic sewage mixed with a pungent smell, polluted the entire shallow water system of the village. 
In 2011, during the spring drought season, farmers in Mengjiawu Village, Wen'an County, pumped the Xiaobai River to water the wheat fields, and the wheat was almost out of production. There are waste plastic processing bases and steel plants in the upper reaches of the river. The river is black and smelly, and there are often dead fish floating up.

In March 2013, The Ministry of Environmental Protection's inspection team found a comprehensive investigation of the Hebei steel industry, $60 \%$ of the operating enterprises in the province have environmental problems, and $70 \%$ of the dust removal facilities are not operating properly, eighty percent of enterprises lets out wastewater in violation of regulations. among them Wen'an Xinzhen Iron and Steel Company, Anci District Haoyuan Metal Products Co., Ltd. became a typical punishment.

August 2013, due to the water pollution of the chemical plant, Hebei Huanghua Zhongjie Farm 16th Team, Zhongjie Farm Field Department, Liuguanzhuangcun and Xinzhuangzicun became "cancer villages".

In 2013, the survey data of the Ministry of Housing and Urban-Rural Development showed that, more than two-thirds of cities are surrounded by garbage, the accumulation of garbage has accumulated and occupied 80,000 mu of land.

In 2014, Beijing's daily production of garbage reached 18.4 million tons, and the annual amount of garbage increased by $8 \%$.In 2015 , Beijing produced 21,600 tons of domestic garbage per day, and it is expected to rise to 28,000 tons per day in 2020 .

In February 2014, ashes appeared in most parts of central and eastern China. The area of impact is about 1.43 million $\mathrm{km}^{2}$, and the area of heavy reclamation is about $810,000 \mathrm{~km}^{2}$. Mainly concentrated in Beijing, Hebei, Liaoning, Shanxi, Shandong, Henan and other places.

November 2014, in Beijing-Tianjin-Hebei, there are more than 20 funnels in the groundwater over - exploitation area, covering an area of $70,000 \mathrm{~km}^{2}$. The land subsidence region area is $90,000 \mathrm{~km}^{2}$. The area of severe settlement with an annual settlement rate of more than $30 \mathrm{~mm}$ is about $25,300 \mathrm{~km}^{2}$. In some areas, the annual maximum settlement is $160 \mathrm{~mm}$, which causes the groundwater quality to deteriorate.

In 2016, the Ministry of Environment of China reported that, 40,000 townships and towns and nearly 600,000 administrative villages in nationwide, More than 280 million tons of domestic garbage are produced each year, and the number has exceeded that of cities.

On April 18, 2017, there were two industrial sewage seepage pits of 170,000 square meters and 30,000 square meters in Nanzhaofu Town, Dacheng County. Sampling analysis showed that the soil was strongly acidic and the metal chromium exceeded the standard. In the last seven or eight years, the number of cancer patients in the village has increased.

In April 2017, the problem of "Scattered and dirty pollution" in the wood-based panel industry in Zuogezhuang, Daliuhe and Tanli districts of Wen'an County was supervised by the Ministry of Environmental Protection.

\section{Migration and enrichment characteristics of elements between biological and environmental medias and its ecological environment effects}

\subsection{The migration allocation and growth decline relationship between elements in human hair and soil}

Using 21 sets of soil-crop-human hair matching samples from Langfang area, the authors analyzed the distribution, migration and transformation of life elements in the nutrition or food chain.

The ratio of element content (absorption coefficient) in different media at the same sampling location is a quantitative indicator for measuring the absorption and utilization of elements in regional ecosystems. Human hair/soil element content ratio, the order from big to small is as follows: N166, Cl4.11, Se3.05, Hg2.77, Zn2.37, Fe1.32, Cd0.78, I0.72, $\mathrm{Cu} 0.53$, Pb0.24, Mo0.22, P0.21, F0.47, Cr0.11, Co0.058, Ca0.023, Mn0.010, Mg0.009.

Between the total amount of soil elements - human hair elements, I0.5881,Co 0.3525, Mg0.3083, F0.2504, N0.1964, $\mathrm{Se} 0.1830, \mathrm{Ca}, \mathrm{Pb} 0.1242$, there is a weak positive correlation, Cl-0.3215, Fe-0.3037, P $-0.1790, \mathrm{Mn}-0.1790$, there is a weak negative correlation. 
Between soil available elements - human hair elements, Zn0.3255,N0.1807,Fe0.1456,there is a weak positive correlation.

In the deep $(-130 \mathrm{~cm})$ soil elements $(\mathrm{x})$ - human hair elements $(\mathrm{y})$, the Hg element is significantly logarithmically positive correlation:

$$
y=0.0104 x^{3}-1.3246 x^{2}+52.752 x-414.03 R^{2}=0.7066 n=28
$$

\subsection{Relationship between Industrial and agricultural production and soil elements}

To study the relationship between elemental content and crop yield, the author established a multivariate regression equation between the economic indicators of grain, vegetables, fruits, oils in 2001, and soil elements in the nine cities and counties of Langfang.

Autumn grain yield (kg/ha) $\gamma=0.8636$

$\mathrm{Y}_{1}=4797+1838 \lg [(\mathrm{P} \times \mathrm{N} \times \mathrm{K} \times \mathrm{Mn}) /(\mathrm{Cl} \times \mathrm{B} \times \mathrm{As} \times \mathrm{Mg})]$

Oil production $(\mathrm{kg} / \mathrm{ha}) \gamma=0.8166$

$\mathrm{Y}_{2}=9238+1464 \lg [(\mathrm{P} \times \mathrm{Zn}) /(\mathrm{Cl} \times \mathrm{B} \times \mathrm{Cr} \times \mathrm{As})]$

Melon fruit (kg/ha) $\gamma=0.8788$

$\mathrm{Y}_{3}=265155+21621 \lg [(\mathrm{P} \times \mathrm{K} \times \mathrm{I}) /(\mathrm{Se} \times \mathrm{As} \times \mathrm{N} \times \mathrm{Cu} \times \mathrm{F} \times \mathrm{Pb} \times \mathrm{Cr} \times \mathrm{B} \times \mathrm{Fe})]$

Farmers' net income (yuan/year) $\gamma=0.8379$

$\mathrm{Y}_{4}=3401+84[(\mathrm{Mo} \times \mathrm{Hg} \times \mathrm{Mn} \times \mathrm{P} \times \mathrm{K}) /(\mathrm{pH} \times \mathrm{Ca} \times \mathrm{Cd} \times \mathrm{Mg} \times \mathrm{B} \times \mathrm{Cl})]$

Industrial output value (ten thousand yuan $/ \mathrm{km}^{2}$ ) $\gamma=0.8768$

$\mathrm{Y}_{5}=129+0.0266[(\mathrm{Hg} \times \mathrm{N} \times \mathrm{Pb}) /(\mathrm{pH} \times \mathrm{Ca})]$

Among them, Om is organic, $\mathrm{N}^{*}$ is hydrolyzable nitrogen $\eta \mathrm{g} / \mathrm{g}$, $\mathrm{P}^{*}$ is available phosphorus $\eta \mathrm{g} / \mathrm{g}, \mathrm{Mn}^{*}, \mathrm{Zn}^{*}$, and $\mathrm{Mo}^{*}$ is effective manganese zinc molybdenum $\eta \mathrm{g} / \mathrm{g}$.

As can be seen from the above formula, organic matter, hydrolyzable nitrogen, available phosphorus, available manganese, zinc, molybdenum, etc. , has a positive effect on promoting regional economic development. However, indicators such as calcium, magnesium, chlorine, boron and $\mathrm{pH}$ have a negative impact. The development of industrial production can lead to the pollution of harmful mercury, lead and three nitrogen in the soil environment.

\subsection{Historical and cultural celebrities}

Gong Jinzhong et al. pointed out that, between the social function of the famous celebrities in Langfang and the geochemical characteristics of the soil at the birthplace, show a not accidental relevance. In the Gu'an, Yongqing, Guangyang and Anci areas of the Yongding River Basin, the content of harmful elements such as $\mathrm{Pb}, \mathrm{Cd}, \mathrm{As}, \mathrm{Hg}$ in the soil is low, groundwater quality is excellent, this superior ecological geological environment, its historical celebrities are mostly bureaucratic scholars; The Wenan, Dacheng and Bazhou areas of the Daqing River and Ziya River basin, $\mathrm{Pb}, \mathrm{Zn}$, $\mathrm{Cu}, \mathrm{As}, \mathrm{Hg}, \mathrm{F}, \mathrm{Cl}$ and other harmful or excessive harmful elements in the soil are higher. Coupled with fragile agricultural production conditions such as low terrain, flooding overflow, and high groundwater mineralization, the historical celebrities in the area are mostly destructive uprising leaders, warlords, eunuchs, and gathered in Wen'anwa, Baicaowa, Yiliuwa and other depression lakes ${ }^{[18]}$.

\section{Cancer map drawing and distribution characteristics}

By the end of 2015, the number and coverage of the Chinese Cancer Registry has increased significantly, It has reached a high level in the world, but the quality of registration data needs to be improved [19]. Urgently needed work is to 
regularly publish cancer-related information, systematically organize relevant data such as tumor registration, cause of death monitoring, geographic information, and compile national cancer maps.

\subsection{Access to morbidity mortality data}

In the process of investigating land use information for key enterprises in environmental pollution, by personally interviewing local residents on the spot, the author obtained data on cancer incidence and mortality at the village level. Ask a question: What is the total number of cancer patients and population in your village in recent years? Interviewees: simple, 50 65 year old male farmers and industrial workers who care about public affairs, a small number of $40 \sim 50$ year old rural cadres and medical workers. The data density is 1 point $/ 24 \mathrm{~km}^{2}$, which is equivalent to a $4.5 \mathrm{~km} \times 4.5 \mathrm{~km}$ grid.

\subsection{Data Analysis}

Calculate the number of all types of cancer patients / current population, we have obtained the latest gross mortality and incidence $\left(10^{-4}\right)$ data of malignant tumors in recent years. Among them, the rural areas are based on natural (administrative) villages as a unit, and the urban areas are based on communities as a unit. The author did not perform age standardization.

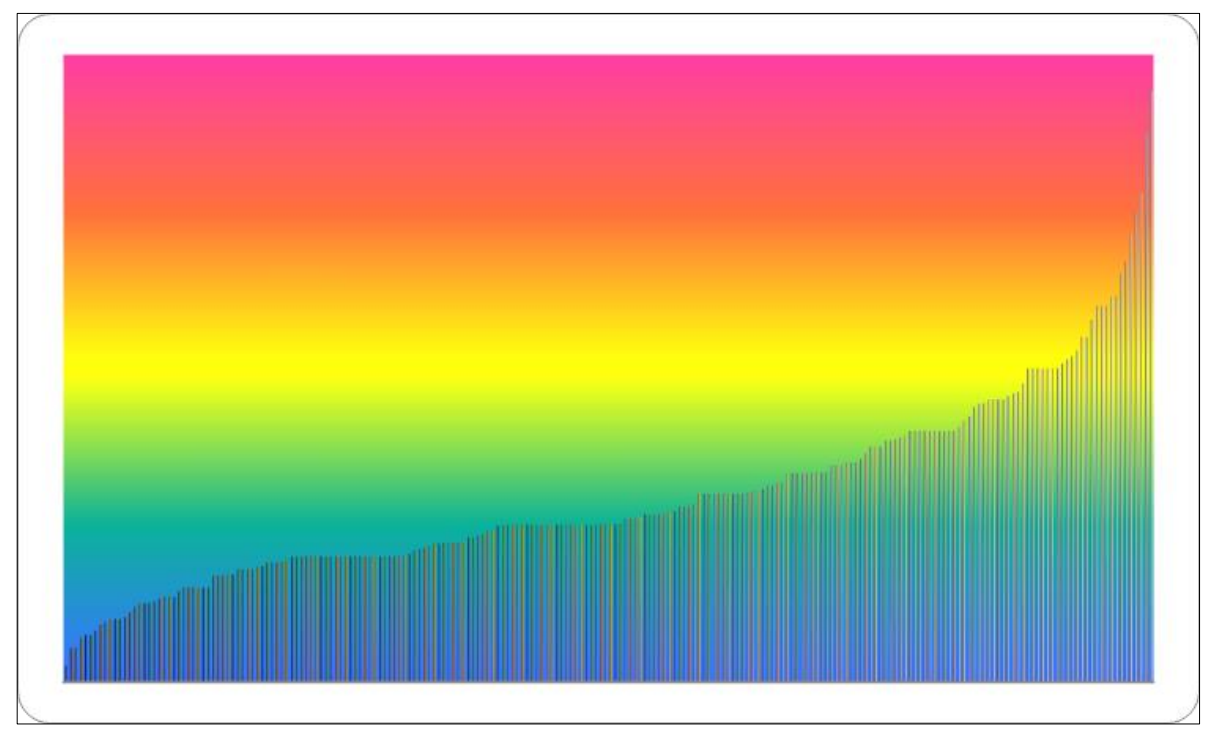

Figure 1 Sequence diagram of residents cancer incidence and mortality in Beijing-Tianjin Corridor region

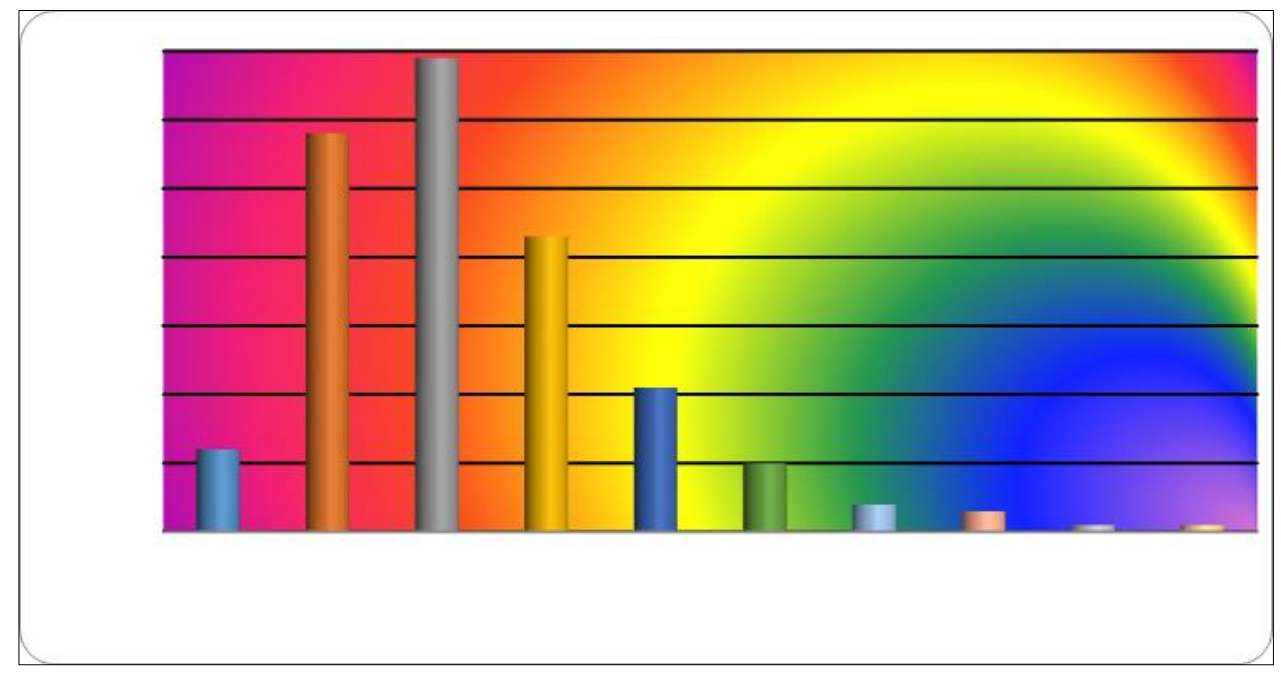

Figure 2 Probability distribution histogram of residents' cancer incidence + mortality in Beijing-Tianjin Corridor region 
Drawing production: On the MapGIS operating platform, the geographic base map is used as the background, the cancer data is labeled according to the village, and the equal-line is drawn by hand, and the partition is filled with color. The cool color indicates a low value area, and the warm color indicates a high value area. The southern part of Langfang is actual measured data, and other areas are inferred based on relevant data.

Range of numerical changes is 2.5/104 94.3/104, arithmetic mean average29.66, standard deviation15.02, median25, asymmetry skew1.271. The probability distribution is a normal distribution with a superposition of positive values.

\section{Geographical spatial distribution characteristics of resident cancer}

On the resident cancer map, the characteristics of cancer distribution in this area are as follows.

- Beijing, Tianjin, Langfang and other large and medium-sized cities is high-incidence areas, generally above $50 \times 10^{-4} \sim 60 \times 10^{-4}$, and the general county towns and some townships is also high.

- The vast rural areas show a significant zonal distribution, Jizhou-Sanhe North Foothills, Yongding River Channel and Gu'an Mangniu River Basin the northeast-oriented strip area is the lowest, $10 \times 10^{-4} \sim 20 \times 10^{-4}$, gradually increasing to the southeast low-lying area, reached its highest level along the central Daqing River,50 $\times 10^{-}$ $4 \sim 60 \times 10^{-4}$. From the central to the southwest, the numerical value has decreased as the terrain has increased.

- $\quad$ Some local high-value points (villages) are scattered in the low-value area of the northwest.

\section{Related analysis of cancer and hydrological soil environment}

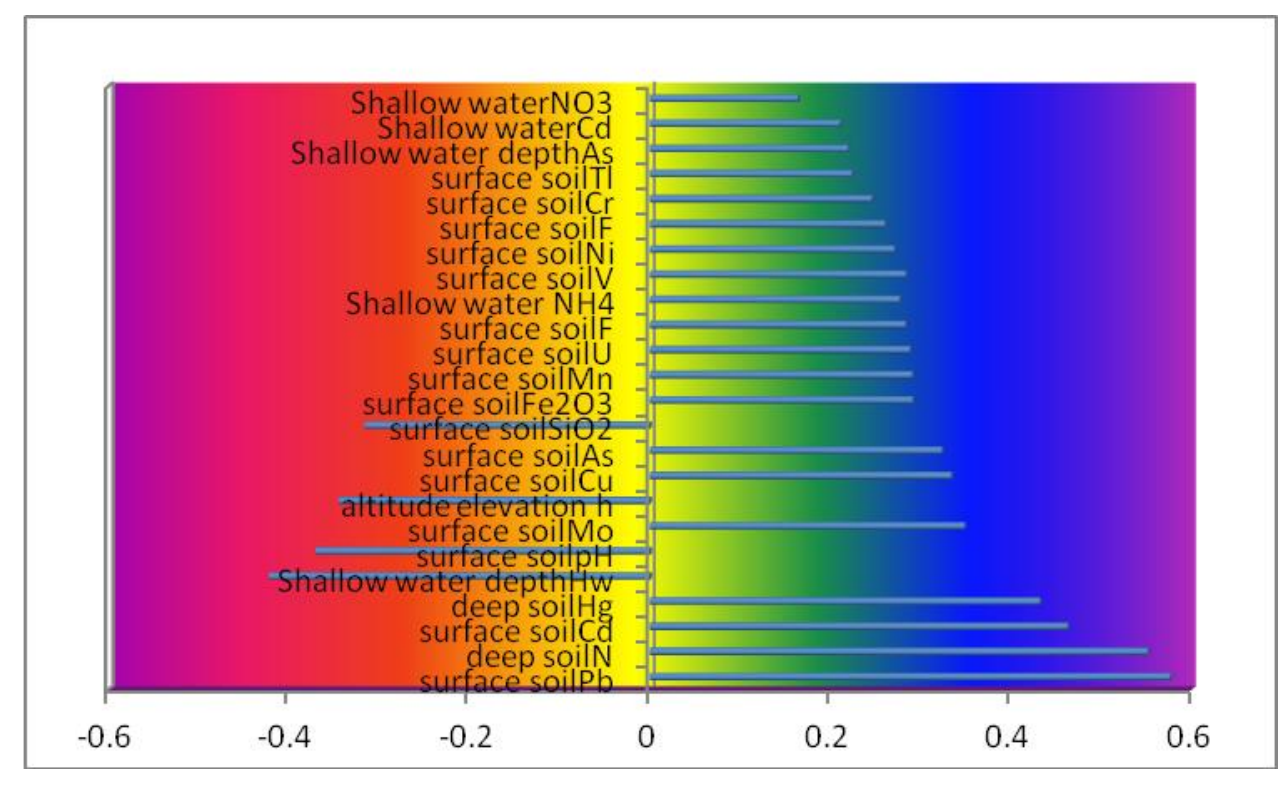

Figure 3 Correlation coefficient pedigree of resident's cancer and environmental indicators in Beijing-Tianjin Corridor

Using the 1:50,000 geological environment survey in the planning area of Langfang City in 2005 [20], and the multitarget geochemical survey data of the 1:25 million Hebei Plain in 2008, the correlation between soil and water element content and cancer distribution was analyzed, the results showed a significant negative correlation $\quad\left(n=222, \gamma_{0.05}=0.163\right.$ ) : Shallow water depth of water -0.4218 , surface soil pH-0.3702, altitude elevation -0.3448 , surface soil $\mathrm{SiO}_{2}-0.3158$, significant positive correlation: surface soil Pb0.5769,surface soil Cd0.4629,deep soil (-1.3m) N0.5518,deep soil Hg0.4321,surface soil Mo0.3486,surface soil Cu0.3340,surface soil As0.3234,surface soil Fe $\mathrm{O}_{3} 0.2913$, surface soil Mn0.2906,surface soil U0.2882,surface soil F0.2833, shallow groundwater $\mathrm{NH}_{4}$-N0.2768, surface soil V0.2835,surface soil Ni0.2707, surface soil F0.2604,surface soil Cr0.2460, surface soil Tl 0.2241, shallow groundwater As 0.2199 , shallow groundwater $\mathrm{Cd} 0.2109$, shallow ground water $\mathrm{NO}_{3} 0.1644$.

Analysis of 45 samples in the planning area of Langfang City, the resident's cancer mortality rate is negatively correlated with the shallow depth of groundwater table $-0.5271\left(n=45, \quad \gamma_{0.05}=0.2040\right)$,significant positive correlation indicators: deep soil Hg0.8885,surface soil Pb0.8572,shallow groundwater Cr0.8290, deep soil N0.7106,surface soil effective Zn0.7027, surface soil Cd0.6931,surface soil Hg0.6751, shallow groundwater $\mathrm{NH}_{4}$-N0.6441, surface water Zn0.6288, 
shallow groundwater As0.6206, shallow groundwater $\mathrm{NO}_{3}-\mathrm{N} 0.6130$, shallow groundwater $\mathrm{Pb} 0.5284$, shallow groundwater $\mathrm{Cd} 0.5028$, shallow groundwaterNO $\mathrm{N}_{2}-\mathrm{N}, 0.4958$. Except for the buried depth of the water level, they are harmful or excessive harmful elements, directly or indirectly indicating the presence of carcinogens (dioxin, benzopyrene, etc.).

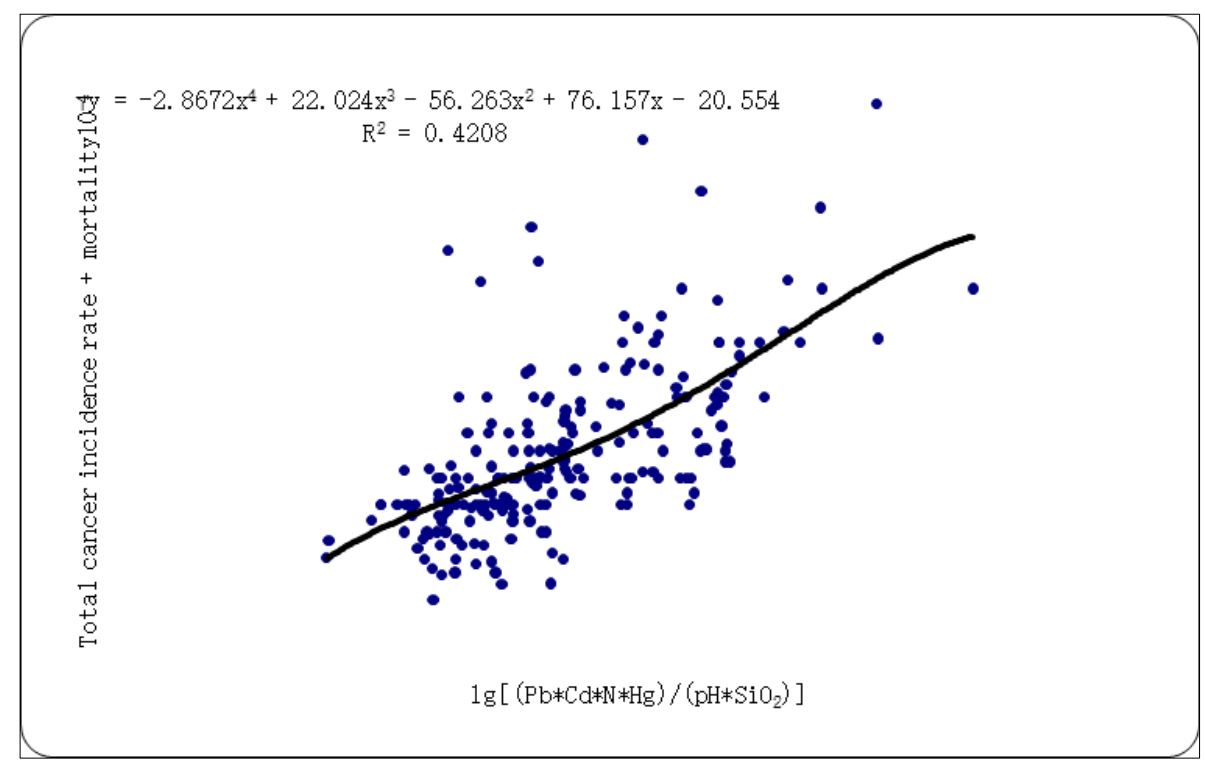

Figure 4 Scatter plot of soil geochemical index X and resident's cancer distribution y in Beijing-Tianjin Corridor

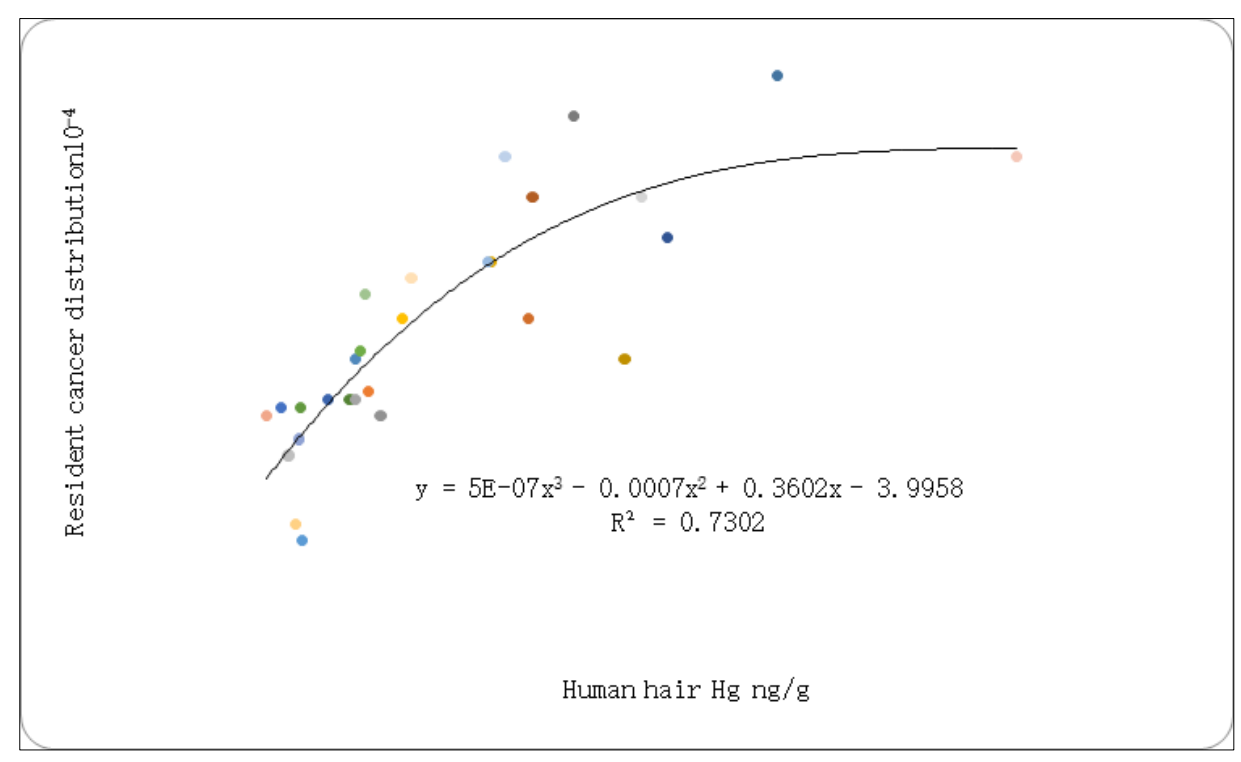

Figure 5 Scatter plot of human hair Hg and resident's cancer distribution in Langfang, Hebei

Between the soil geochemical index $\mathrm{X}$ and the resident's cancer distribution, we can establish a good functional relationship:

$y=-2.8672 x^{4}+22.024 x^{3}-56.263 x^{2}+76.157 x-20.554$

$\mathrm{R}^{2}=0.4208 \gamma=+0.6487 \mathrm{n}=222 \gamma_{0.05}=0.133$

$\mathrm{x}=\lg \left[(\mathrm{Pb} \times \mathrm{Cd} \times \mathrm{N} \times \mathrm{Hg}) /\left(\mathrm{pH} \times \mathrm{SiO}_{2}\right)\right]$

Between the Hg content of human hair and the distribution of cancer, we can establish a polynomial equation: 


$$
\begin{gathered}
y=5 E-07 x^{3}-0.0007 x^{2}+0.3602 x-3.9958 \\
R^{2}=0.7302 \gamma=0.8545 n=28 \gamma 0.05=0.374
\end{gathered}
$$

According to the characteristic pollutant frequency table of 340 enterprises in key industries in Langfang area, the correlation coefficient of organic pollutants and mercury was calculated: benzopyrene 0.4723 , pyridine 0.1551 , formaldehyde 0.1371 , dioxin $0.1138\left(n=340, \gamma_{0.05}=0.1056\right)$. These are carcinogens.

\section{Geological environment model of cancer distribution}

Based on the results of this study, the authors established a mode map of the relationship between water soil geochemical anomalies (contamination sources) -rocky soil hydrological conditions (migration pathways), and cancer distribution (sensitive receptors) in Langfang.

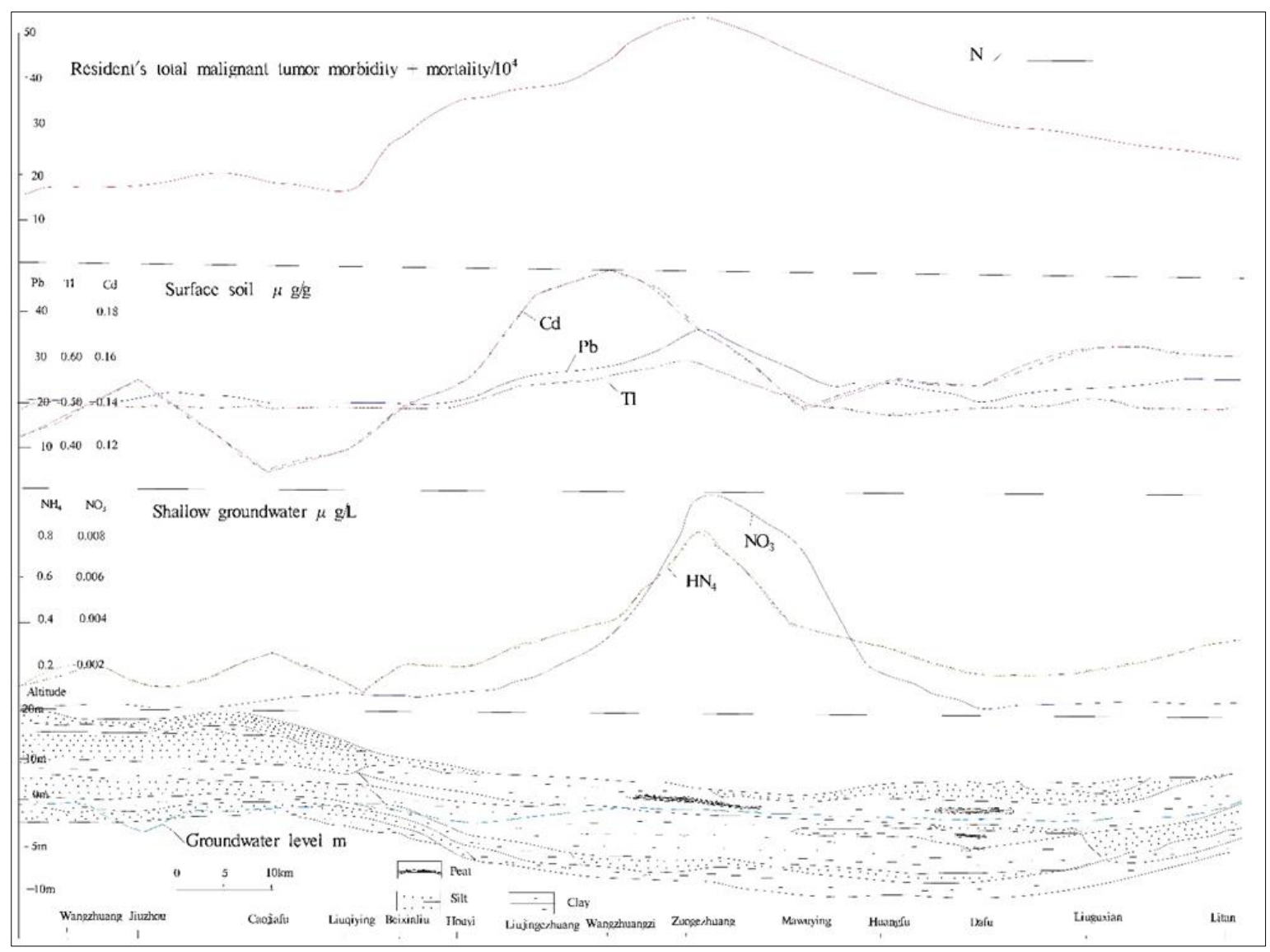

Figure 6 Geological environment model map in resident's cancer distribution of Langfang, Hebei

\begin{tabular}{|c|c|c|}
\hline $\begin{array}{c}\text { Cancer } \\
\text { distribution }\end{array}$ & $10 \times 10^{-4} \sim 30 \times 10^{-4}$ & $40 \times 10^{-4} \sim 60 \times 10^{-4}$ \\
\hline Historical figures & Bureaucrat, scholar & Eunuch, uprising leader \\
\hline Social economy & Farming, Planting, nurture & Industrial commercial trade \\
\hline Plant community & Fruit, vegetables, sweet potatoes & Sorghum, cotton, reed, jujube \\
\hline Altitude elevation & $15-30 \mathrm{~m}$ & $10-2 \mathrm{~m}$ \\
\hline Landform form & $\begin{array}{l}\text { Flooding alluvial fan, slow slope, Ancient river } \\
\text { highlands and micro-highlands }\end{array}$ & $\begin{array}{l}\text { Low-lying land, Low level ground, Flood } \\
\text { plain }\end{array}$ \\
\hline Soil type & $\begin{array}{l}\text { Fluvo-aquic soils, brownish fluvo-aquic soil, } \\
\text { salinized fluvo-aquic soil }\end{array}$ & Wet fluvo-aquic soil, meadow-boggy soil \\
\hline
\end{tabular}

Table 1 Geological environmental factors for cancer distribution in Langfang 
World Journal of Advanced Engineering Technology and Sciences, 2021, 03(02), 024-037

\begin{tabular}{|c|c|c|}
\hline $\begin{array}{l}\text { Sedimentary } \\
\text { lithology }\end{array}$ & T-sandy loam soil, S- sandy soil & Y- clay, SY- mild clay \\
\hline $\begin{array}{l}\text { Accumulation } \\
\text { cause }\end{array}$ & $\mathrm{Qh}_{\mathrm{h}}^{\mathrm{fpf}}$ Alluvial and pluvial fan, $\mathrm{Qh}_{\mathrm{h}}^{\mathrm{fc}}$ channel belts & $\begin{array}{l}\text { M-Alluvial clip Sea accumulation, } \mathrm{Q}_{\mathrm{h}}{ }^{\mathrm{fic}} \\
\text { interstream area }\end{array}$ \\
\hline Soil composition & High pH, Enrichment Na, Sr, I & $\begin{array}{l}\text { Enrichment N, F, Cl, Cr, Ni, Co, Cu, Pb, Zn, As, } \\
\text { Mo, Se and many more }\end{array}$ \\
\hline Water level & $30 \sim 10 \mathrm{~m}$ & $10 \sim 2 \mathrm{~m}$ \\
\hline Water chemistry & High pH, $\mathrm{Fe}$; low $\mathrm{Cl}_{1} \mathrm{SO}_{4}{ }^{2-}, \mathrm{NO}_{2}-\mathrm{N}$ & Low $\mathrm{pH}, \mathrm{Fe} ; \mathrm{High} \mathrm{Cl}_{1} \mathrm{SO}_{4}^{2-}, \mathrm{NO}_{2}-\mathrm{N}$ \\
\hline
\end{tabular}

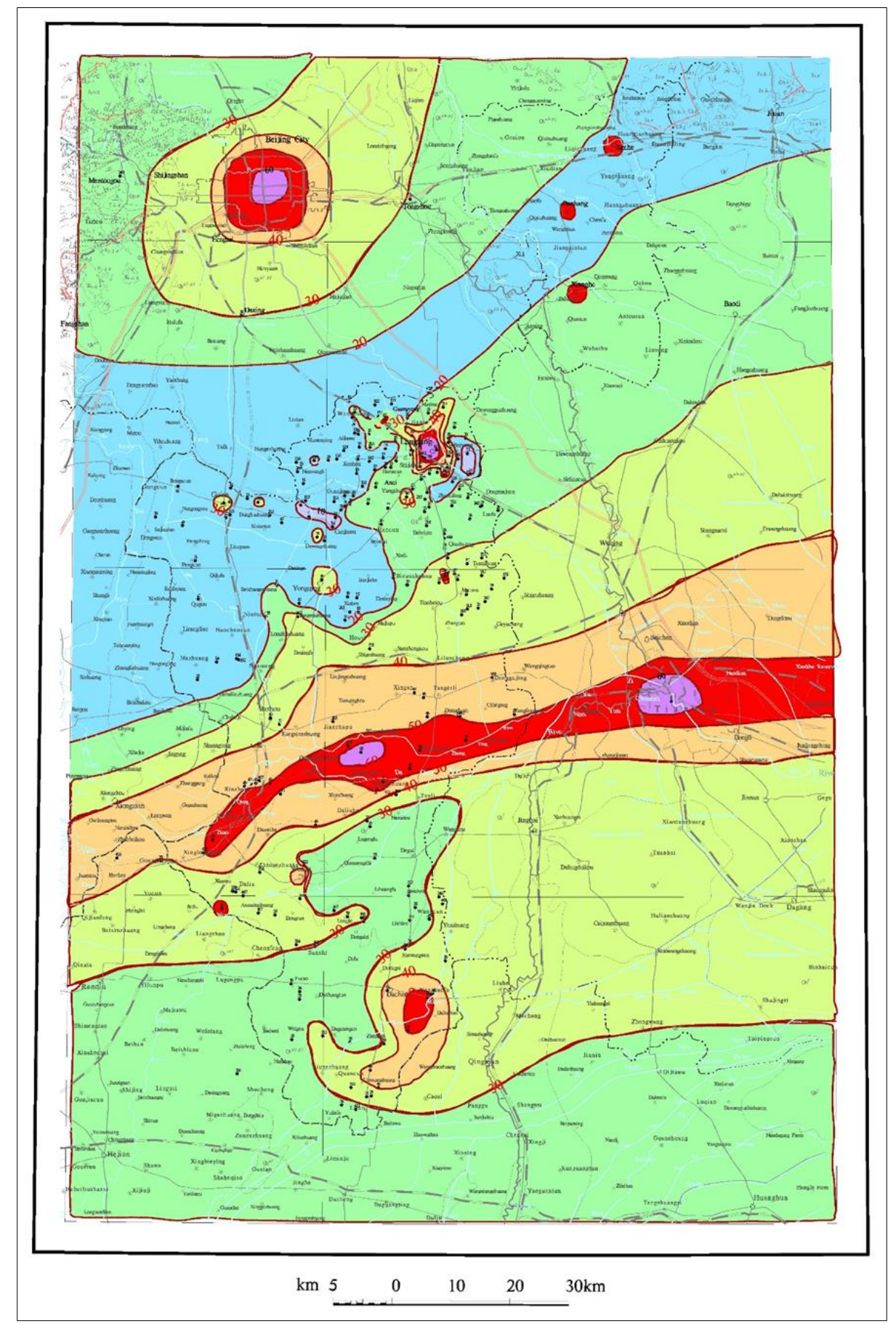

Figure 7 Distribution map of resident cancer total gross morbidity mortality rate $\left(10^{-4}\right)$ of Beijing-Tianjin Corridor in 2017 2018 


\section{Conclusion}

The corridor region between Beijing and Tianjin in China, the author obtained data on cancer morbidity and mortality at the village level, its value ranges has significant zonal distribution characteristics. This article established a mode chart of the relationship between geochemical anomalies (contamination sources) of soil waters- geotechnical hydrological conditions (migration pathways)-resident cancer distribution (sensitive receptors). This research has important guiding significance for the epidemiology and preventive medicine of cancer.

\section{Compliance with ethical standards}

\section{Acknowledgments}

The relevant leaders and colleagues of the fund project provided the author with work help and convenience, Those residents interviewed by the author, provided a lot of useful information. I hereby express my sincere thanks!

\section{Fund Project}

China Ministry of Ecology and Environment Key industry enterprise land survey information collection Affairs Office Soil letter [2018] No. 924.

\section{Disclosure of conflict of interest}

There is no conflict of interest in this article.

\section{Statement of ethical approval}

This study does not involve human experiments.

\section{References}

[1] Wang Xiaomei. Analysis on the Distribution Characteristics and Environmental Factors of Common Digestive System Cancers in China [J]. Journal of West Anhui University. May 1999; 15(2): 57-59.

[2] ZENG Zhao-hua,ZENG Xue-ping. The Correlation between esophageal cancer and elements in soil environment in China [J].Henan geology. Mar 2000; 18(1): 76-80.

[3] LI Hongtu. The Study on the Association of Ecological Environment and Plasma Trace Elements and Their Related Metabolic Genes SNPs with Gastric Cancer in Xianyou County [D]. Fujian University of Medicine. 2016: 2-5.

[4] LIU Tongshan. Economic Development, Environmental Pollution and the Health of Residents-Research on Cancer Village Based on Media Analysis [J]. Ecological Economy. 2016; 32(7): 14-19.

[5] Li Jiaxi, Wu Gongjian, Huang Huaizeng, et al. Geochemical environment: Agriculture - Health [M], Beijing: Geological Publishing House. 2001; 1-18.

[6] Chen Zhu, Chief Editor. Report of the third China National retrospective Sample survey on Causes of death [M], Beijing: China Union Medical University Press. 2008;1-51.

[7] CHEN Wanqing, ZHENG Rongshou, ZHANG Siwei. Cancer Incidence, Mortality and Trend in China [J].Science \& Technology Review. 2014; 32(26): 65-71.

[8] Chen W, Zheng R, Baade PD, et al. Cancer statistics in China, 2015. CA Cancer J Clin [J]. 2016; 66(2): 115-132.

[9] Zeng Hongmei Chen Wanqing. Cancer Epidemiology and Control in China: State of the Art, PROGRESS IN CHEMISTRY. Sep 2013, 25(9): 1415-1420.

[10] Maigeng Zhou, et al. Cause-specific mortality for 240 causes in China during 1990-2013: a systematic subnational analysis for the Global Burden of Disease Study 2013 [J]. The Lancet. 2015.

[11] Shi Jin. Status and prediction of malignant tumors and deaths in Hebei Province in 2014 [R]. Master's thesis of Hebei Medical University. 2017; 1-2.

[12] Gong Sheng-sheng, Zhang Tao. Temporal and Spatial Distribution Changes of Cancer Village in China .China Population, Resources and Environment [J]. 2013; 23(9): 156-161. 
[13] JZ Gong. Environmental impact analysis of mine tailing reservoir, International Conference on Water Resource and Environment 2016 (WRE2016), IOP Conf. Series: Earth and Environmental Science. 2016; 39: 012014.

[14] Hou Chuntang, Liu Xiaodun. North China plain Water and Soil Geological Environment portfolio [M], Beijing: Geological Publishing House. 2010; 19-161.

[15] Zhang Weili, Tian Zhexu, Zhang Ning, et al. Investigation of Nitrate Pollution in Ground Water due to Nitrogen Fertilization in Agriculture in North China, Journal of Plant Nutrition and Fertilizer, Jol. 1996; 1(2): 81-87.

[16] Li ZC. Present situation and prevention countermeasures for agricultural non-point pollution in China. Modern Agricultural Science and Technology. 2012; 14: 213-214.

[17] Liu Qinpu. Spatio-temporal changes of fertilization intensity and environmental safety threshold in China [J], Transactions of the Chinese Society of Agricultural Engineering. 214-221.

[18] Gong Jinzhong, Li Guangping. Biogeochemical cycle and its eco-environmental effects in Hebei Province, multitarget regional geochemical survey and evaluation anthology [M], Beijing: Geological Publishing House. 2011; 135-139.

[19] Chen Wanqing, Liang Zhiheng, Cen Huishan.Current Status and Development of Chinese Cancer Registry [J], Chinese Journal of Frontier Medicine (Electronic Edition). 2016; 8(7): 1-5.

[20] Shi Shujuan, Gong Jinzhong, Jin Sichao, et al. Geochemical evaluation of soil environmental pollution in the planning area of Langfang City [J]. Geophysical and Geochemical Exploration. 2008; 5: 571-573. 